HOW

Volume 29, Number 1, pages 173 - 193

https://doi.org/10.19183/how.29.1.622

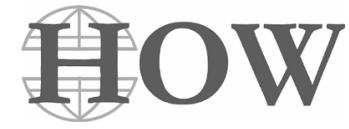

\title{
The Use of Social Networks in L2 Instruction: Discussing its Opportunities and Obstacles
}

\author{
El Uso de las Redes Sociales en la Enseñanza de un Segundo \\ Idioma: Discutiendo las Oportunidades y Obstáculos
}

\author{
Perla Villegas-Torres ${ }^{1}$ \\ Universidad de Guanajuato, Guanajuato, Mexico
}

\begin{abstract}
This article presents a discussion and analysis on the implementation of social networks to support the learning of a second language (L2) in the field of Computer Assisted Language Learning (CALL); an area that has regained especial significance in the post pandemic era. Through a cumulative case study report that compares and contrasts several research studies carried out at different times, this article first brings to discussion the strengths that social networks offer for their implementation in L2 instruction. To continue the discussion, the issues of teachers' CALL training and access are presented as weaknesses for a successful implementation of social networks in the L2 instruction. It is argued that social networks cannot work as effective tools for this purpose without the guidance of a properly trained instructor. Nevertheless, attaining such an ideal condition is challenging considering the problems that might emerge during its implementation. Although it is common that language teachers to some extent include this resource for their L2 classes, more research needs to be done to produce literature that sheds light on the aspects that need to be worked on to take real advantage of this type of technology.
\end{abstract}

Keywords: CALL, feedback, L2 attitudes, language learning, motivation, social networks

She holds a masters' degree in Applied Linguistics in English Language Teaching from Universidad de Guanajuato, Guanajuato, Mexico 2018. Currently she works as a Professor at the Universidad de Guanajuato. She has presented her work in Germany, the United States, and Mexico.

p.villegastorres@ugto.mx

ORCID ID: https://orcid.org/0000-0003-3153-0920

Received: October 8th, 2020. Accepted: October 14th, 2021.

This article is licensed under a Creative Commons Attribution-Non-Commercial-No-Derivatives 4.0 International License. License Deed can be consulted at https://creativecommons.org/licenses/by-nc-nd/4.0. 


\section{Resumen}

Este artículo presenta una discusión y análisis sobre la implementación de redes sociales para apoyar el aprendizaje de una segunda lengua (L2) en el campo del Aprendizaje de Idiomas Asistido por Computadora (AIAC); un área que ha ganado un significado especial en la etapa posterior a la pandemia. Por medio de un informe de estudio de caso acumulativo que compara y contrasta varias investigaciones llevadas a cabo en diferentes tiempos, este artículo primero trae a discusión las fortalezas que ofrecen las redes sociales para su implementación en la instrucción L2. Para continuar con la discusión, los temas de la capacitación de los docentes y acceso al AIAC se presentan como debilidades para una implementación exitosa de las redes sociales en la instrucción L2. Se sostiene que las redes sociales no pueden funcionar como herramientas efectivas para este propósito sin la guía de un instructor debidamente capacitado. Sin embargo, lograr una condición tan ideal es un desafío considerando los problemas que podrían surgir durante su implementación. Si bien es común que los profesores de idiomas incluyan en alguna medida este recurso en sus clases de L2, es necesario realizar más investigaciones para producir literatura que arroje luz sobre los aspectos en los que es necesario trabajar para aprovechar realmente este tipo de tecnología.

Palabras clave: aprendizaje de idiomas asistido por computadora, redes sociales, aprendizaje de idiomas, motivación, actitudes hacia el segundo idioma, retroalimentación

\section{Introduction}

In the context of the 2020 post-pandemic era and the upsurge implementation of distance learning due to the lockdown of schools, computer assisted language learning (CALL) offers a range of possibilities for supporting the learning of an additional language. Since this field needs further exploration, there are counter positions about what types of technologies could be the most appropriate to promote the acquisition of an additional language. Several authors have proposed the use of social networks as an effective alternative to learn a second language (Dehghan et al., 2017; Laghos \& Nisiforou, 2018; Mellati et al. 2018; Umarqulova, 2020; among others). Nevertheless, several controversial standpoints can also be found in the literature of this field. This article presents a cumulative case study report with the aim of evaluating the different perspectives regarding the implementation of social networks as means for learning a second language. According to Hayes et al. (2015), cumulative case studies obtain data from a number of topic-related and previously conducted case studies,

174 that even when they correspond to different sites and times, are all tied together by the same focus of study. For such a reason, this paper looks at studies related to the implementation of social networks in language learning that span from the beginning of the year 2000 to the present in order to compare and contrast the evolution of this field.

In the first part of this article, the advantages for the implementation of social networks in the instruction of a second language are discussed. They include: the contribution to the normalization of CALL, the implications for students' motivation and attitudes, the social 
networks' multimedia assets, as well as the opportunities for collaboration and feedback. In the second part, the drawbacks for the implementation of social networks in second language instruction are addressed, and these include access and integration.

\section{What Do We Mean by Social Networks?}

To begin the discussion, it is essential to define the key term of this article. In a broader sense, Wasserman and Faust (1994) define 'Social networks' as a set of nodes interconnected through one or several relations. From this definition, it can be understood that every node is represented by a person who is socially related to others, and who can maintain links which may fall into diverse categories such as kinship, friendship, fellowship, and even professional, academic, or business relationships, among others.

Eventually, social networks were extrapolated to the virtual world. In the field of Information and Communication Technologies (ICTs), the first years of the $21^{\text {st }}$ century were marked by the remarkable appearance of Web 2.0 which had as its main characteristic the allowing of collaboration, participation, and exchange of content and ideas by internet users (Miller, 2005). It was such a significant change in the history of the World Wide Web since the information sharing stopped being one-sided to become mostly interactive. In fact, internet users went from passive receptors and information processors to active contributors and content creators: social networks had been born.

It is now convenient to provide a definition of the term belonging to the ITCs milieu. Boyd and Ellison (2007) define social networks as the

Web-based services that allow individuals to (1) construct a public or semi-public profile within a bounded system, (2) articulate a list of other users with whom they share a connection, and (3) view and traverse their list of connections and those made by others within the system." (p. 211)

Based on this definition, examples of social networking online platforms currently used are Facebook, Twitter, Instagram, Pinterest, WhatsApp, LinkedIn, Snapchat, Tumblr, YouTube, etc. These platforms allow users to establish social relations with other people providing a space for interactions based on the publication of multimedia content to express their opinions, experiences, interests, ideas, common knowledge, activities, achievements, etc.

\section{Early Research on Social Networks and Language Learning}

One of the first attempts to set a precedent in this field was made by Lomicka and Lord (2009), who carried out a qualitative case study focused on computer-supported collaborative learning of foreign language graduate students from three universities in the U.S. They 
used a wiki, which fits with the characteristics of a social networking site. Using the Curtis and Lawson framework (2001), they conducted an analysis of the learners' collaborative behaviors. Their findings showed that the students' level of involvement was not equal, which affected the quality of collaboration. This aspect might set an important factor for the analysis herein described, since even contributions and interactions must be performed by students in order to successfully carry out a learning task. This issue might also be related to the lack of a well-established pedagogical objective that includes the teacher's systematic supervision and feedback. The authors also concluded that qualified research in this field lacked both from theoretical and empirical perspectives. Even though in recent years studies on the use of social networks applied in language learning has considerably increased, it still requires further exploration.

Additionally, González Arroyo (2011) highlighted the collaborative advantage that social networks offer for language teachers due to their constant exchange amongst users. She also remarked on the usefulness of social networks for decreasing anxiety, increasing motivation, and fostering autonomy. Accordingly, in their study, Akbari et al. (2016) analyzed the relationship between the use of social networks for educational purposes on/as regards learners' engagement, motivation, and learning. The methodology consisted of comparing two controlled groups: one using face-to-face education and the other using Facebook. Their findings showed that the Facebook group showed higher outcomes on the TOEFL. Additionally, the Facebook group showed higher levels of engagement and motivation by the end of the course. As this study showed, the socio-emotional factor is presumably one of the greatest advantages of promoting the use of social networks in the field of language learning since it is an activity with which people continually interact in their daily lives.

Lin, Warschauer, and Blake (2016) conducted a survey of 4,174 participants, as well as 20 individual case studies involving Chinese speakers who were English language learners. The study evaluated learners' attitudes, usage, and progress in their L2. They identified as a drawback that most learners dropped out or showed only limited advancement. Their most significant finding was that learners need support, guidance, and well-structured activities to ensure successful participation and linguistic interaction. The next section presents recent literature on this matter, which seems to confirm and expand upon this latter idea.

\section{Recent Literature in the Area}

Recently, the production of literature in the field of CALL and social networks in language learning has increased. Derakhshan and Hasanabbasi (2015) present a review of several previous studies which have analyzed Facebook and E-mail as tools to promote language learning. After analyzing these studies, they report that Facebook presented the most significant effect on language learning; both Facebook and E-mail are mainly perceived 
as advantageous for improving the writing skill. Additionally, they emphasize incidental learning as an important feature of social networks, which represent a source of stimulation/ motivation to learn the second language. Certainly, social networks provide motivation for L2 learners, although not only for writing but also in other areas as they stimulate the listening, reading, and speaking skills due to the multimedia information that is shared on them.

Similarly, Deghan et al. (2017) set up a study to compare the progress that learners would have via using WhatsApp to teach all the L2 vocabulary from the corresponding textbook with the traditional face-to-face methods used in a classroom (e.g., vocabulary lists, drills repetition, flashcards, etc.). With this aim, two groups of EFL learners were evaluated using a pre-test and a post-test vocabulary assessment. The results showed that there was not a significant difference between the performance from one group and the other. In their discussion, the authors' interpretation for that result includes the learners' negative attitudes towards the use of social networks, as well as the lack of guidance, rules, and feedback from the teacher, as well as a solid establishment of a pedagogical purpose. They also sustain social networks should not be prescinded from classroom instructions. This study suggests that the advantages of using social networks in L2 learning might become idle/diminished when there is no a clear guidance and objective established by the language teacher.

Another study analyzing WhatsApp as a tool to teach vocabulary was carried out by Mellati et al. (2018). The objective of this research was to investigate the impact of creative interaction in social networks on learner's vocabulary. Having this purpose, they integrated 90 L2 learners to participate in the study and analyze their WhatsApp interactions. The researchers created a pre-test and post-test to measure their advancement in their vocabulary repertoire, as well as a semi-structured interview to gauge/measure the learners' own perceptions on their progress. Their findings remarked on the opportunities for effective interaction that technology presents, and the challenges that it implies for learners living in developing countries. Among the shortcomings of using social networks for language learners, these researchers mention the excess of freedom and the many distractors/ distractions that learners face when interacting; as well as the need of having an adequate internet infrastructure and literacy to be able to successfully manage these tools. Once again, the issue of having a focus and pedagogical objective arises as a determinant factor to successfully implement social networks as a language learning tool.

McManus (2019) analyzed the social networks (Facebook and Skype) interactions of 29 British university French learners who were participating in an academic exchange for a ninemonth stay in France, with the aim of tracking the learners' L2 complexity development. The data collection technique was a social network questionnaire to collect data in the beginning, middle, and end of their stay. The study concludes that the more French speaking contacts the learners had, the more complex their use of language would become in their online exchanges. In the same manner, constant communication with contacts in their home 
country would slow down their language development. In this study, the interactions were completely free, in a context unrelated to any classroom assignment. The objective was only to examine the learners' behavior in their interactions; thus, the results confirm that both the guidance of the teacher and the pedagogical purpose are essential to take advantage of social networks as tools to learn and practice an L2.

In this section, some of the previously done research related to the use of social networks in L2 learning have been presented. In the following sections, the discussion pinpoints a number of the obstacles and opportunities of implementing social networks within the L2 context to take advantage of them as tools to promote the use of the target language.

\section{Social Networks as an Alternative to the Normalization of CALL}

Firstly, as an argument in favor of the use of social networks, the potential contribution that they might offer to the normalization of CALL is brought to discussion. According to Bax (2003), a central issue regarding CALL is to achieve its normalization. It consists of attaining a status in which technology is so embedded or integrated into the language classroom that teachers and students can make use of it naturally, in an almost unnoticed way. Chambers and Bax (2006) consider that although the elements to make the normalization of CALL possible may differ from context to context, they may be mainly based on improvements in the size, design, and location of the technology. In my opinion, social networks might offer an important contribution to the normalization of CALL. The main reason for arguing this is the level of familiarity that social networks have reached worldwide in the last years. That is, people from all ages, nationalities, and social backgrounds do have access to this type of technology on a daily basis.

In October 2018, the website Statista reported that the most famous social network sites worldwide ranked by number of active users are Facebook with 2234, YouTube with 1900, WhatsApp with 1500, Instagram with 1000, Weibo with 431, and Twitter with 335 million users. Those numbers serve to understand the fact that social networks have become part of people's everyday life; thus, the benefits that they may offer should be exploited. Even in

178 the immediate context, one can noticed that people from different ages use social networks to communicate. They have revolutionized the ways in which people communicate. Today social networks are the medium for people to express their feelings, get informed, look for a job, make friends, fall in love, etc.

Due to their easy accessibility, social networks seem to comply with the three elements proposed by Chamber and Bax (2006). First, location; social networks can be potentially everywhere with an available internet connection. Second, size; social networks can be accessed 
through a smart phone, tablet, or computer allowing mobility and portability for users. Third, design; social networks have a user-friendly and attractive design that allows people from different parts of the world to get access to them in an easy manner. Furthermore, they are an effective manner with which to access to the globalized world since people from around the world are users of different social networks, as has been mentioned before. Therefore, their potential for being used in the learning of different languages is evident.

In the local context, Izquierdo et al. (2017) carried out a study to explore the situation of teacher's use of technologies of information and communication in southern Mexican public schools, and the level of normalization that these technologies have among teachers. They collected data through the application of Likert-scale questionnaires, interviews, and classroom observations. The results showed that apart from having limited access to the computer equipment, there was also a lack of training, technical support, and time availability. Concerning this same issue, in their study in the Iranian context, Hedayeti and Marandi (2014) interviewed twelve teachers with similar educational backgrounds, but with different experiences in using technologies in the classroom (four with experience, four with no experience, four who had just finished the CALL course). They found that the obstacles to achieve the normalization of CALL can be classified in three categories: teacher, facility, and learner constraints. The study was carried out with a relatively small number of participants; thus, its reliability might not be strong enough, and it may cause other factors to be left aside. Nevertheless, it stills provides insights into the issues that affect the normalization of CALL.

In the first category regarding teachers' constraints, the study found as the more recurrent problems the lack of CALL training, lack of digital literacy, teachers' attitudes and resistance, and lack of support from other stakeholders, among others. Within the second category, which is the facilities, the study indicated that the limited availability or lack of digital technologies at schools and deficient internet connection were the main obstacles for normalization. Finally, in the category of learners' constraints, the study found that the main issues were related to the level of proficiency, autonomy, age, insufficient computer literacy, and technology access problems. Although the previously mentioned studies belong to two different contexts (Mexico and Iran), their results go hand in hand in regard to the general constraints that L2 teachers might face for the normalization of CALL.

Nevertheless, social networks seem to have the capacity to overpass many of these constraints. For instance, since social networks were designed aiming to be user friendly, the level of digital literacy, age, and autonomy needed might not be factors that impede their use. In the same manner, as previously mentioned, social networks are already part of our daily lives so that the resistance that teachers and students might have been already tackled by social networks; the only pending issue, which becomes relevant, is to create activities with a pedagogical purpose (Lin, Warschauer, \& Blake, 2016). 
As previously highlighted, in spite of the user-friendly characteristics of social networks, the main challenge is the teachers' ability to create well-directed activities headed to comply with a pedagogical purpose. This statement is supported by Hsu (2016), who claims that the effectiveness of the integration of technology into the language classroom depends on teachers' technological, pedagogical, and CALL knowledge. He reached this conclusion after conducting a quantitative study on 158 surveys of Taiwanese EFL teachers to learn whether teachers' perceptions were related to their technological and pedagogical knowledge. One of the findings of the study was that although teachers possessed technological knowledge, they lacked the pedagogical knowledge needed for creating effective learning activities. This latter seems to be a significant shortcoming for the advantages that so far has been pinpointed as being in favor of the use of social networks in language learning instruction. A deficient pedagogical knowledge to take advantage of social networks draws back the advantage of having the accessible technologies. The latter implies that teachers become aware of the importance of implementing tasks and activities that not only involve the use of social networks, but also activities with a pedagogical purpose. Those activities should aim to put into practice a specific language feature. In the same manner, those tasks should allow students to have collaboration among themselves, so that they can share and build their knowledge with each other. Furthermore, the teacher should be able to evaluate effectively the students' progress and provide feedback.

This section has described the way the implementation of social networks might serve as an alternative to promote the normalization of CALL. As Mellati et al. (2018) assert, stakeholders and government need to work hand in hand to support financially the normalization of technologies and train teachers in digital literacy. The following section presents another advantage that social networks might offer in L2 learning, which consists of boosting students' motivation to continue with their progress in the target language.

\section{The Effect of Social Networks on Students' Motivation and Attitudes When Learning an Additional Language}

At first appearance, it may be argued that the use of social networks in language learning is an excellent tool to enhance motivation and positive attitudes of learners. Nevertheless, examining this hypothesis from different perspectives is necessary. In this regard, Ayres (2002) conducted a study to learn about students' attitudes towards the use of CALL. A total of $157 \mathrm{~L} 2$ undergraduate students, enrolled in a 16-week foreign language course, were interviewed. The methodology of the course was mainly based on the intensive use of a diversity of language software. The results showed that although the participants reported to have a low level of computer skills, they had in general a positive attitude towards the use of CALL. Similarly, they considered CALL as a tool to enhance classroom-based teaching. 
However, the fact that the students reported their own level of digital literacy without being evaluated in that aspect needs to be pondered, since their perceived level of digital literacy might not be backed up with their actual skills. Although the study does not address social networks per se, its findings can be cautiously taken as analogous. Knowing that there is evidence of students having a certain degree of acceptance towards CALL and thus social networks can be well accepted, the next point to discuss is exactly what students may find in social networks to increase their motivation.

In addition to authentic social networks, there are also others created with a pedagogical purpose. Examples of the social networks to learn languages that can be found on the World Wide Web, these are Livemocha, Busuu, Lingualia, Babel, Speaky, UniLang, HiNative, Languing, among others. The use of these social networking platforms results in a practical strategy to improve students' motivation and positive attitudes towards the L2 learning.

To illustrate this point, Felix (2004) carried out a study on 36 university students enrolled in an L2 web-based course. The data collection techniques included journals and surveys to obtain feedback about their perceptions using web-based language learning. The study found specific aspects that students perceive as advantages and disadvantages on learning a language through this type of resources. Among the advantages: time flexibility, wealth of information, reinforcement of learning, privacy, ability to repeat exercises, gaining computer literacy, and absence of teacher. These advantages can be noted in social networks: users can access at any time, they can receive plenty of input in the L2 from the content that other users publish, they also might get feedback in the L2 from the people they interact with, or they may have private interactions which decrease the anxiety to commit mistakes; while using the social networks they improve their technology skills, and finally, they can use them in an autonomous manner.

Regarding the disadvantages: lack of speaking practice, distraction, no interaction with peers, inadequate feedback, absence of teacher, and technical support. Given that the study was made in 2004, and being now situated in the year 2021, several of the stated disadvantages have been removed: most social networks now allow videoconferencing, which can be used to practice speaking and interact with other users, as well as to receive feedback. The multimedia content can be used to catch students' attention instead of being a factor of distraction. These same platforms are user friendly enough for not requiring technical support, and the teacher's support can be only necessary to assign a task.

It should be mentioned that the cited study has some methodological flaws, such as being too broad on its objectives and the correlation between the intended studied variables. Even so, the results in this specific aspect seem to be consistent with what a student finds motivating from using a web-based social network platform to learn an additional language. For instance, having access to a wealth of information results/constitutes a benefit for 
students who seek to be challenged in their level of proficiency. It is what Vygotsky calls the zone of proximal development, i.e., students need to be in contact with language that is right above their current level in order to advance further and continue learning. Students may have plenty of opportunities to interact with a more advanced written or spoken language while interacting in social networks, even having visuals as support for comprehension such as images, video, etc. Indeed, this is a way of motivation. In addition, the social network platform offers a certain degree of freedom to users, since they have the opportunity to interact with its different features as the language included in the images, texts, videos, option menus, etc. Experimenting by themselves with no restriction of time and attempts, etc., results a motivating experience for students.

A more recent study carried out by Mellati et al. (2018) obtained similar findings. In their study, which had as an objective to determine the effect of creative interactions in social networks on learners' vocabulary knowledge, they applied pre and posttests to evaluate the learners' vocabulary level, as well as semi-structured interviews of 90 language learners. Among the positive effects, L2 learners reported that social networks are authentic, effective, and suitable for learning outside the classroom environment. Moreover, the limitations that they perceived included the lack of digital literacy, economic resources, differences in the L2 level and the challenges that the implementation involves for developing countries.

Another similar study was conducted by Alqahtani (2018). Her study had as a main concern to explore the usefulness of social networks sites to support English language students. Data collection was carried out through questionnaires applied to 45 female participants, who were also social network users, in a Saudi University. The researched confirmed that social networks serve as meaningful and motivating means to improve the learners' L2. They manifested to have positive attitudes towards the use of social networks since they are already part of their daily lives. Additionally, they offer opportunities for collaboration and socialization beyond the school context; therefore, social networks also strengthen social ties which become a great element for increasing motivation.

Another source of motivation that social networks might offer when being used in second language instruction is that they provide a certain level of anonymity. This issue was addressed by Melchor-Couto (2016) in her research studying oral interactions in a virtual

182 world second life. In spite of the number of participants being small, her findings suggest that the fact of enjoying a certain level of anonymity endowed participants with a sort of shield that gave them confidence to speak in the second language. Even though social networks do not function with "avatars", they also provide users with a certain degree of anonymity; users of social networks do not interact face to face, and their real identity does not necessarily need to be exposed. Although most of the information in social networks will promote reading, writing, and listening, it is also possible for users to practice speaking when broadcasting a video, through video calls or voice calls (depending on each social 
network). In any case, learners can enjoy anonymity and the benefit of reducing anxiety to communicate in another language.

This section has presented several studies conducted over a time span of 20 years, which have shed light on the relation between the use of social networks in language learning and the learners' motivation to progress in the L2. Nevertheless, the results have been consistent throughout time, confirming that these tools are effective to support language learning and boost learners' motivation. In the following section, the multimedia features that social networks have are discussed.

\section{Social Networks and Their Multimedia Assets}

One of the greatest advantages of the implementation of social networks in language learning instruction has to do with their multimedia feature. Since social networks allow sharing information through texts, audios, videos, and images, the potential possibilities to create learning activities are countless. Nonetheless, considering the specific standards in order to judge the adequacy of the social networks interface becomes a relevant issue. Concerning this aspect, Ferney and Waller (2001) mention that regarding text, the font size needs to allow enough readability, as well as to avoid overcrowding the screen with large amounts of text. Similarly, they mention that in order to have an efficient interface, other aspects that need to be observed are screen semiotics (to guide the reader through the website), ergonomics (relating to the size of the text, for instance), and an interesting third element which is a virtual relationship. The authors define this third element as a dialogue between teacher and learner through the mediation of a computer. They discuss that when this virtual relationship intends to be cross-cultural, the website might become depersonalized and cultural bias might be induced. Even though every social network is different, most of them comply with the elements described by Ferney and Waller (2001). Regarding the issue about the virtual relationship, social networks have a great advantage. First, their interface is a general one for people around the world who normally do not include/exhibit/possess any type of cultural inclination. At the same time, users can personalize their accounts by means of the content they post. In this way, every account is the reflection of the user's personality and interests; an aspect that results in being a strength for social networks.

The aim of this article is to discuss the possibilities of integration of social networks in the instruction of an additional language. Izquierdo (2014) maintains that people construct their own knowledge during their interaction with different types of media. Nevertheless, for learning to occur, those different types of media must be combined in a way that allows learners to process meaning in the L2. This is why instructors must create meaning-oriented tasks that will allow students to get exposed to rich sources of input from different sources (media) from which they will decode information in the second language. Although it is 
not explicitly mentioned, a third implicit element emerges in this process: the teacher as a mediator between the student and the CALL component. Hence, one cannot ponder a given social network as effective for learning languages without first looking at the instructor as a central partaker in this process.

Also related to this topic is Ranalli's (2008) study on computer simulation games. Aspects of this study can be comparable with the present discussion on the availability of incorporating social networks to second language instruction. For instance, a similarity of simulation games and social networks is that both provide rich opportunities for linguistic exposure and communitive practice due to their multimedia content within meaningful contexts. This study offers a specific example of how a technology-based resource can be adapted to be used for pedagogical purposes. In this case, the researcher added instructions to complete a task, vocabulary lists, notes explaining cultural content, access to an online dictionary, and allowed collaboration with other learners. The study found that the participants considered this adaptation to have potential for language learning, but as an addition to the course-based instruction. In sum, when comparing social networks, they can be seen as an excellent medium for facilitating the instruction of an additional language, as long as the process is mediated by a language teacher who is properly trained to use this type of technologies.

\section{The Possibility of Collaboration and Feedback:}

\section{A Social Network Strength}

A solid argument to implement social networks in second language instruction is the possibility/opportunity for collaboration and feedback that they offer. Users can post and edit messages, chat with other people, comment on videos and images, and receive feedback on their own contributions. Since social networks allow for connection with people from all around the world, users can interact with native speakers, so that in addition to the language rich input to practice the four skills, they can also get enriched culture-wise.

Previous studies have shown that this type of online resources can be used to promote collaborative learning skills (Alqahtani, 2018; Laghos \& Nisiforou, 2018; Umarqulova,

184 2020). In the same way Zou, Wang, and Xing (2006) conducted a study on the use of wikis (which have similar but more basic features than social networks) integrated in the language classroom. Their aim was to explore the effect of collaborative tasks in error correction for learning Chinese and English for learners in the U.K. and China, respectively. For ten weeks, the learners developed several tasks in a collaborative writing project, in which they also had the opportunity to give feedback to their counterparts under the instructors' monitoring. The participants in the study were even trained on using Wiki including editing and correcting mistakes so that they could prepare students at the same time to perform corrective feedback 
effectively. The methodology of this study was a big strength since the students required to be guided during the process and not being left aside. The results were encouraging since the learners provided positive comments on using Wikis for collaborative learning to practice their language skills and give feedback through the activities designed for this purpose. Moreover, the results suggest that the students improved their writing skills.

Another study conducted by Hung and Higgings (2016) compared the interaction through text-messages and video calls among students. The participants were six Chinese-speaking learners of English and six English-speaking learners of Chinese arranged in dyads. Their aim was to identify the communication strategies that they used, since cultural differences would be mediating the interactions. One pitfall of this methodology is that the learners were given topics and questions to develop the dialogues with their interlocutors which could have affected interactions at the level of accuracy, authenticity, interest/motivation, and pressure. Their findings suggested that video exchanges promote fluency while texts messages are more appropriate to improve accuracy in writing. The cultural differences played an important role since the students explained certain aspects to their peers abroad to enable and facilitate communication. Despite its methodological limitations, this is another example of how to create activities using the social networks as a medium to obtain benefit from their useful resources.

\section{Can Teachers Handle the Integration of Social Networks in Second Language Instruction?}

So far most of the discussed points have to do with the aspects in favor of the use of social networks in second language instruction. However, there are also arguments against its implementation. One of these arguments is the actual possibilities for teachers to create activities that allow students to take advantage of the benefits that social networks entail/ offer, but without losing sight of the pedagogical purpose that they must have.

In Hedayeti and Marandi's (2014) study, whose methodology has been previously described, they found that two of the most significant obstacles for expanding the use of CALL are the lack of teacher training, and their negative attitudes towards its implementation. Other studies have already focused on examining this topic, such as the case of Kuure et al. (2016) who conducted a study on pre-service teachers in order to support them in the process of changing their paradigm from the role of traditional language teachers to technologybased task designers. Their findings suggested that rather than designing activities that represented innovative ways to integrate technology into the classroom, teachers replicated the traditional classroom activities using a computer. Their conclusion established that the central issue in this failure to successfully integrate social networks in the L2 classroom is that these teachers do not view themselves as designers of technology-based activities; thus, they 
do not assume this role. As a solution, the researchers propose that teachers get involved in experimenting with technology and reflecting at the same time on these practices.

In effect, teachers tend to replicate the same strategies with which they were taught, an effect known as apprenticeship of observation (Lortie, 1975), perpetuating in this way the same pedagogical practices generation after generation. An example of this situation can be given when teachers use a Facebook group only to post grammar charts for their students to study. It is natural then that such teachers become reluctant to accept a drastic change as it implies to implement technology-based activities, which challenges their already established teaching-styles and strategies.

Therefore, although using social networks to promote the learning of an additional language seems an appealing idea, the problem of their teacher-mediated adaptation for the language classroom is what makes it difficult to put into practice. This is a serious problem since one of the main characteristics of social networks is precisely this possibility of interacting and connecting with people from different parts of the world. However, Kuure et al's (2016) study found that teachers do not promote collaboration among students, but only individual traditional work. Several authors have also addressed the constraints that language teachers face in order to successfully integrate social networks as tools to support the language learning (Izquierdo et al., 2017; Jafarkhani et al., 2017; Mellati et al., 2018; Umarqulova, 2020). They all coincide on the fact that language teachers require a systematic support from all the involved stakeholders (teachers, government, curriculum designers, administrative staff, etc.) in order to provide adequate training to develop enough digital literacy so as to be able to take advantage of these resources. In this sense, I consider that teachers should be trained in fostering collaboration among students, and this is the main feature of social networks. They allow exchanges among users, and teachers have the possibility of guiding the process of input-output and feedback by taking advantage of various resources that social networks offer.

There are also cases in which teachers perceive the implementation of technology in their classes in a positive way. In their study, Karsenti et al. (2020) examined the attitudes that Slovenian student-teachers had towards the use of digital technology in education and their self-perception about their proficiency when using them. They collected data from 261 student-teachers, using Likert-scale questionnaires to evaluate four categories: teaching and learning, assessment and critical thinking, empowering learners, and facilitating learners' digital competence. The obtained results indicated that the student-teachers hold positive attitudes towards the use of digital technology in the language classroom; however, they perceived themselves as having a low level of digital literacy. I can conclude that teachers need to be supported to overcome the lack of digital literacy, which requires the implementation of training programs. 
The previously regarded collaboration feature of social networks was further studied by Fuchs (2016). She examined tele-collaboration among a group of English language teachers in the U.S. and another one in Turkey. They were asked to develop technology-based English language learning tasks, so that they had to negotiate their design, implementation, and evaluation. The participants had the opportunity to share their opinions, classroom contexts, and learning experiences with the aim of evaluating the pedagogical, technological, and collaborative factors. An important element of this methodology was the use of weekly telecollaborative logs which served as a medium to record their observations, reflections, and articulations about the designed tasks with their teammates, at the same time that they built connections with each other. The implementation of these activities can be easily replicated using social networks, whose attractive features may increase the participants' interest in collaborating. In this aspect, Fuchs' (2016) study put into practice the elements that Kuure et al. (2016) proposed, which were the experimentation with technology and reflection on the process. Only one of the teams reached a high level of collaboration, negotiating their decisions with an efficient management of task-orientation. Once again, I argue that social networks might boost this level of participation and interest. The most relevant aspect of Fuchs's (2016) findings is that through collaboration, reflection, and negotiation, teachers can overcome the initial resistance and take charge of the implementation of technologybased activities. Through a process of efficient peer-work, teachers may create successful activities with strong pedagogical objectives using social networks

Consistent with the latter, Lord and Lomicka (2011) sustain that what is needed to support language teachers in providing the next step to embrace technology (to implement social networks for the purposes of this discussion) is adequate training. They report that training courses for teachers in CALL are scarce, and those who have the possibility to receive one do not feel satisfied with the content they are given. The authors also mention a number of factors that generate that scarcity in the available CALL training courses such as: lack of time in the programs to promote CALL or the vision of technology in language learning as secondary or not considering it important. In their article, the authors sustain that such teachers already have a genuine interest in incorporating technologies in the language classroom but that their main interest is in knowing how to do it.

As Wilson-Armour (2020) sustains, the role of the instructor demands a more invested and active role when implementing technology in the classroom and the need of training and mentoring during the design and implementation process in order to successfully learn to implement technologies in the language classroom. Only then will the implementation of social networks to enhance language learning instruction be possible. At present, several authors are already working on finding strategies to support language teachers in planning and integrating technologies in the classroom. An example of this is Chen's (2019) claim that such an integration should include a constructivist approach based on engaging and real-life 
purpose projects that will allow teachers to capitalize on the online existent resources, such as social networks. The author suggests that projects involve problem-solving, task completion, evaluation, and student reflections. Similarly, Lubkov et al. (2020) propose an implementation of technology from a humanitarian perspective. It means that certain values should be promoted when using digital technologies such as responsibility, communication, freedom, and security. All these values can ensure a more natural transition to the normalization of digital technologies in the language learning class.

In this section I presented various constraints that teachers face to integrate social networks in language learning. The following section discusses the problem of accessibility as a shortcoming to carry out its implementation.

\section{Are Social Networks Accessible Enough?}

I have already referred to the easy manner in which social networks can be accessed. As mentioned before, everyone with a smartphone, tablet, laptop or computer with an internet connection can obtain an account in one of the many available social networks. Nevertheless, the issue of the digital divide looks at the fact that whereas some people have access to different technological resources, there are others who, due to their personal context or location, cannot access to those technologies; a problem that has alarmingly emerged more during this 2020-2021 pandemic lockdown of schools. If CALL was to be included in a curriculum, that would require for education policymakers to review first whether students are in social and economic conditions of equality so that the issue of access is solved beforehand.

Nevertheless, one must consider the variety of contexts in which students can be located. Most countries around the world are developing ones, and even inside a particular country, as is the case of Mexico, students can belong to different social strata, and schools themselves may not possess/provide the necessary equipment or internet connection as to be able to ask every student to work on a given technology-based task. That situation is exemplified in Izquierdo et al's (2017) study. The researchers, as an objective, had to determine which technologies of information and communication had become normalized in public schools in the south of Mexico. They carried out a study combining both quantitative and qualitative data using a Likert-scale questionnaire, interviews for teachers and principals, and longitudinal classroom observations. The researchers found that the main limitations to the normalization of these technologies were the lack of access to the equipment, and the teachers' lack of training / competence to adequately optimize the already limited available technologies. Nevertheless, when considering the setting of a private institution in the center of Mexico, the situation about the access of technology can be considered as the opposite. In 
this manner, the implementation of social networks for language learning should be subdued to the previous acknowledgment of students' equal access conditions to the internet.

Other authors sustain that the issue of scarce technology can be overthrown. That is the case of Egbert and Yang (2004). They argue that optimal language learning activities can be supported by the use of limited technologies. The authors maintain that despite the available technological resources, teachers can make a good use or poor use of them. In this aspect they add that regardless of the many multimedia features that the World Wide Web applications offer (as in the case of social networks), students might feel overwhelmed by these technologies, frustrated or unmotivated due to poor use. In order to demonstrate their point, they present a framework for developing language learning tasks in limited technology contexts. This framework consists of eight conditions: providing learners with possibilities of interaction and negotiation of meaning, interaction with the target language, use of authentic tasks, freedom to use language creatively, going at their own pace and obtaining feedback, guided attention, low levels of anxiety, and allowing autonomy. Once again, this aspect seems to relate to instructors' lack of expertise in becoming designers of technologymediated tasks. Egbert and Yang's (2004) framework guides teachers on the necessary aspects to design appropriate activities.

In the Mexican context, Izquierdo et al. (2017) conducted a mixed-method study with the aim of examining the ICTs that English teachers used in the daily instructional practices with young learners in public schools. One of their findings was that the teachers did not use institutional technology equipment; but preferred to bring to class their own equipment. One reason for this behavior was that the administrative regulations are complicated, so they preferred to make the process easier. This is an example of the struggles that teachers face even when the school provides them with technology equipment. Going back to the implementation of social networks in the second language classroom, one can observe that social networks are designed to be used in an individualized manner. In this way, in order to use them in the language classroom each student requires access to a computer or mobile device with internet connection, either in the classroom or at home. Nevertheless, it is difficult to ensure that every student has the access and technology needed to participate in a given task; situation that is restrained only to certain contexts.

\section{Conclusion}

In this article, I have analyzed different positions in favor and against the implementation of social networks in second language instruction. The studies discussed here provide evidence that suggests that social networks possess a great potential due to their features that allow sharing multimedia information, getting feedback through collaboration, being exposed 
to rich sources of input in the second language, negotiating in meaningful interactions, motivating students with relevant topics, and improving attitudes toward the L2, etc.

Nevertheless, in each of the arguments that I have presented, a common element emerges: in order to benefit students with the advantages that social networks offer, language teachers need to design adequate activities and tasks which lead students to a successful interaction with technology and progress in their L2 learning. This point supposes a great challenge since, as I have discussed, there is a scarcity in the available CALL training programs for teachers; thus, their resistance to integrate technology in the language classroom persists. All the involved stakeholders (government, curriculum designers, administrative staff, language teachers, etc.) should work together to overcome this issue as well as to achieve the objective of taking advantage of the many benefits that social networks have and the potential to contribute to the area of language learning. Supporting teachers to develop a digital literacy might have as a consequence the shift towards building more positive attitudes on working with technology; an element that has become essential in the post-pandemic era.

Another factor that I discussed as blocking the implementation of social networks is the issue of access, although it could be seen as a minor aspect, since it is more linked to each school and student's particular context, and there may be cases in which students and teachers find themselves in a privileged position that allows them to easily access technology. The digital divide is a problem that most developing countries face; nonetheless, it is possible to advance step by step towards the expansion of new horizons of possibilities that teachers can offer to language learners. This will surely allow one to take advantage of the technology that already forms part of people's everyday life as in the case of social networks.

In sum, this article has discussed two conditions for a successful incorporation of social networks in language learning: First, having adequate task-design and guidance by the instructor, and second, having the possibility of access to technology. With these two elements, I consider that social networks can have by themselves all that is needed for learners to become benefited and to enhance their language learning process.

\section{References}

Akbari, E., Naderi, A., Simons, R. J., \& Pilot, A. (2016). Student engagement and foreign language learning through online social networks. Asian-Pacific Journal of Second and Foreign Language Education, 1(1), 1-22.

AlQahtani, N. A. (2018). The effect of social networks on the improvement of Saudi EFL students. 2(8), 150-137." 
Arroyo, C. G. (n.d.). On-line social networks: Innovative ways towards the boost of collaborative language learning. Pixel-Online.Net. Retrieved June 30, 2021, from https://conference.pixelonline.net/conferences/ICT4LL2011/common/download

Ayres, R. (2002). Learner attitudes towards the use of CALL. Computer Assisted Language Learning, 15, 241-249.

Bax, S. (2003). CALL—past, present and future. System, 31(1), 13-28.

Boyd, D. M., \& Ellison, N. N. (2007). Social network sites: definition, history, and scholarship. Journal of Computer-Mediated Communication, 13(1), 210-230.

Chambers, A., \& Bax, S. (2006). Making CALL work: Towards normalization. System, 34, 465-479.

Chen, J. (2019). Designing online project-based learning Instruction for EFL learners: A WebQuest approach. MEXTESOL Journal, 43(2), 1-7.

Curtis, D., \& Lawson, M. J. (2001). Exploring collaborative online learning. Journal of Asynchronous Learning Networks, 5(1), 21-34.

Curtis, D., \& McKenzie, P. (2001). Employability skills for Australian industry: Literature review and framework development. Australian Council for Educational Research.

Dehghan, F., Rezvani, R., \& Fazeli, S. (2017). Social networks and their effectiveness in learning foreign language vocabulary: A comparative study using WhatsApp. CALL-EJ, 18(2), $1-13$.

Derakhshan, A., \& Hasanabbasi, S. (2015). Social networks for language learning. Theory and Practice in Language Studies, 5(5), 1090.

Egbert, J., \& Yang, Y. F. (2004). Mediating the digital divide in CALL classrooms: Promoting effective language tasks in limited technology contexts. ReCALL 16, 280-291.

Felix, U. (2004). A multivariate analysis of secondary students' experience of web-based language learning. ReCALL, 16, 129-141.

Ferney. D., \& Waller, S. (2001) Reflections on Multimedia Design Criteria for the International Language Learning Community. Computer Assisted Language Learning, 14(2), 145-168.

Fuchs, C., (2016). "Are you able to access this website at all?" - team negotiations and macro-level challenges in telecollaboration, Computer Assisted Language Learning, 29(7), 1152-1168.

Gonzalez Arroyo, C. (2011). On-line social networks: Innovative ways towards the boost of collaborative language learning. ICT for language learning.

Hayes, R., Kyer, B., \& Weber, E. (2015). The case study cookbook. Worcester Polytechnic Institute, 1(2), 18.

Hedayeti, H., \& Marandi, S. (2014). Iranian EFL teachers' perceptions of the difficulties of implementing CALL. ReCALL, 26, 298-314.

Hsu, L. (2016) Examining EFL teachers' technological pedagogical content knowledge and the adoption of mobile-assisted language learning: a partial least square approach. Computer $A s-$ sisted Language Learning, 29(8), 1287-1297. 
Hung. Y., \& Higgins, S. (2016) Learners' use of communication strategies in text-based and videobased synchronous computer-mediated communication environments: opportunities for language learning, Computer Assisted Language Learning, 29(5), 901-924.

Izquierdo, J. (2014). Multimedia instruction in foreign language classrooms: Effects on the acquisition of the French perfective and imperfective distinction. Canadian Modern Language Review, $70(2), 188-219$.

Izquierdo, J., De la Cruz, V., Aquino, S., Sandoval Caraveo, M. C., \& García, V. (2017). Teachers' use of ICTs in public foreign language education: Evidence from secondary schools. Comunicar. Revista de Comunicación y Educación, 50, 33-41.

Jafarkhani, F., Jamebozorg, Z., \& Brahman, M. (2017). Application of social networks to support students' language learning skills in a blended approach. Middle East Journal of Family Medicine, $7(10), 89-95$.

Karsenti, T., Kozarenko, O. M., \& Skakunova, V. A. (2020). Digital Technologies in teaching and learning foreign languages: Pedagogical strategies and teachers' professional competence. Education and self-development, 15(3).76-88.

Kuure, L., Molin-Juustila, T., Keisanen, T., Riekki, M., Iivari, N., \& Kinnula, M. (2016) Switching perspectives: from a language teacher to a designer of language learning with new technologies. Computer Assisted Language Learning, 29(5), 925-941.

Laghos, A., \& Nisiforou, E. (2018). Computer assisted language learning social networks: What are they talking about? Social Networking, 7(3), 170-180.

Lin, C. H., Warschauer, M., \& Blake, R. (2016). Language learning through social networks: Perceptions and reality. Language Learning \& Technology, 20(1), 124-147.

Lomicka, L., \& Lord, G. (2009). Introduction to social networking, collaboration, and Web 2.0 tools. In L. Lomicka \& G. Lord (Eds.), The next generation: Social networks and online collaboration in foreign language learning (pp. 281-294). CALICO.

Lomicka, L., \& Lord, G. (2016). Social networking and language learning. The Routledge Handbook of Language Learning and Technology, 255-268.

Lord, G., \& Lomicka, L., (2011). Calling on educators: Paving the way for the future of technology and CALL. In N. Arnold \& L. Ducate (Eds.). Present and future promises of CALL: From theory and research to new directions in language teaching (pp. 441-470). CALICO.

192 Lortie, D. (1975). Schoolteacher: A sociological analysis. University of Chicago.

Lubkov, A. V., Gordienko, O. V., \& Sokolova, A. A. (2020). A humanitarian approach to the digitization of education. Education and Self Development, 15(3), 89 -96.

McManus, K. (2019). Relationships between social networks and language development during study abroad. Language, Culture and Curriculum, 32(3), 270-284.

Melchor-Couto, S. (2016). Foreign language anxiety levels in second life oral interaction. ReCALL, 29(1), 99-119. 
Mellati, M., Khademi, M., \& Abolhassani, M. (2018). Creative interaction in social networks: Multi-synchronous language learning environments. Education and information technologies, 23(5), 2053-2071.

Miller, P. (2005). Web 2.0: Building the New Library. Ariadne, 45. www.ariadne.ac.uk/issue45/ miller/intro.html

Ranalli, J. (2008). Learning English with the Sims: Exploiting authentic computer simulation games for L2 learning. Computer Assisted Language Learning, 21, 441-455.

Umarqulova, M. (2020). Social networks and language learning. Архив Научных Публикаций JSPI.

Wasserman, S., \& Faust, K. (1994). Social Network. Analysis. Cambridge University Press.

Wilson-Armour, C. (2020). Reconceptualizing blended learning as a teaching strategy for English language learners. Mextesol Journal, 43(2).

Zou, B., Wang, D., \& Xing, M. (2016). Collaborative tasks in Wiki-based environments in EFL learning. Computer Assisted Language Learning, 29(5), 1001-1018. 